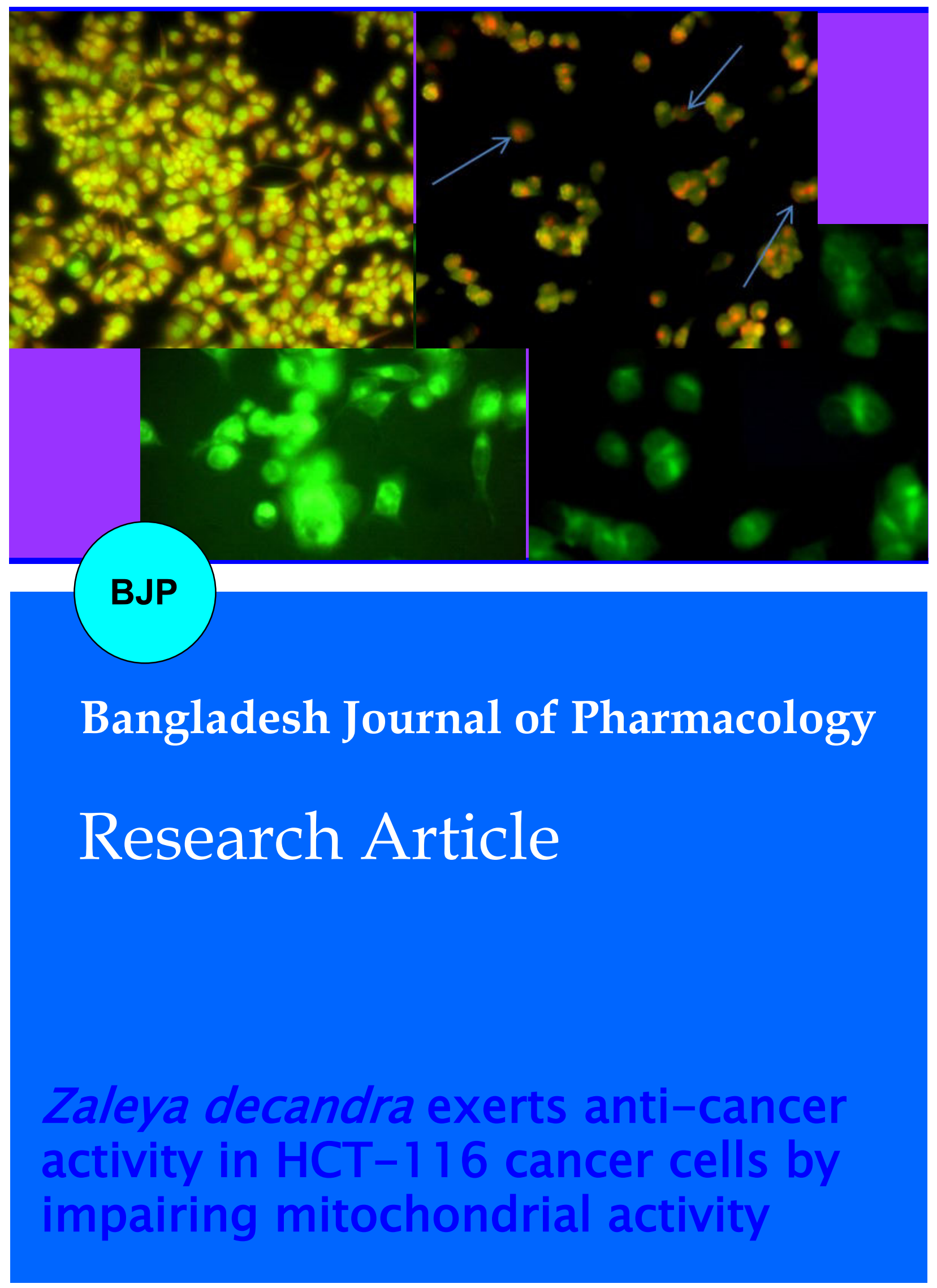




\section{Zaleya decandra exerts anti-cancer activity in HCT-116 cancer cells by impairing mitochondrial activity}

\section{Malarvizhi Deivasigamani, Ajay Kasivishwanathan Chandrasekar, Sridhar Muthusami, Gopalakrishnan Velliyur Kanniappan and Hariprasath Lakshmanan}

Department of Biochemistry, Karpagam Academy of Higher Education, Eachanari, Coimbatore 641 021, Tamil Nadu, India.

\begin{tabular}{|lr|}
\hline Article Info \\
\hline Received: & 9 July 2019 \\
Accepted: & 13 October 2019 \\
Available Online: & 14 December 2019 \\
DOI: $10.3329 /$ bjp.v14i4.42098 \\
\\
\\
Cite this article: \\
Deivasigamani M, Kasivishwanathan \\
CA, Muthusami S, Kanniappan GV, \\
Lakshmanan H. Zaleya decandra exerts \\
anti-cancer activity in HCT-116 cancer \\
cells by impairing mitochondrial ac- \\
tivity. Bangladesh J Pharmacol. 2019; \\
14: 174-80.
\end{tabular}

\begin{abstract}
An attempt has been made to investigate the role of Zaleya decandra on the survival of HCT colon cancer cells in vitro. The cell viability and apoptosis were assessed using MTT assay and acridine orange/ethidium bromide staining, respectively. Mitrochondrial membrane permeability was assessed using rhodamine-123 staining. The activities of caspases were evaluated using ELISA kits. Treatment with $Z$. decandra extract increased the production of ROS in HCT cells and impaired the mitochondrial activity as evidenced by decreased reduction of tetrazolium salt and enhanced mitochondrial membrane permeability. The onset of apoptosis was evident in cells treated with the extact in acridine orange/ethidium bromide staining and was associ-ated with elevated levels of initiator and effector caspases in the conditioned medium. In conclusion, Z. decandra treatment promoted the apoptosis of HCT colon cancer cells.
\end{abstract}

\section{Introduction}

Globally 1.8 million new cases are identified as colorectal cancer and 881,000 deaths occurred in 2018 (Bray et al., 2018).

The treatment employed to date includes metoclopramide, domperidone, haloperidol, ondansetron, chlorpromazine, diphenhydramine, prochlorperazine, olanzapine and dexamethasone (Berger et al., 2016). However, usage of these drugs is associated with various adverse effects (Munker et al., 2018). The immune therapy molecule like cetuximab is also associated with skin rashes (Giuliani and Marzola, 2013; Baas et al., 2018). Collectively these observations indicate the necessity of identifying a drug with a few or no adverse effect.

Various herbs were suggested as anti-cancer drug in the treatment of colorectal cancer which include Coptidis rhizoma and Scutellariae radix (Fukutake et al., 1998), Cissus quadrangularis (Jainu et al., 2010), huangqin decoction (Chen et al., 2016), Panax ginseng and Veratrum nigrum (Kee et al., 2018), Solanum incanum (AlEmam et al., 2018) and grape seed (Zhang et al., 2019).

Previous studies carried out in this laboratory revealed the anti-diabetic potential of ethanolic extract of Zaleya decandra in alloxan-treated Wistar rats (Meenakshi et al., 2010). Z. decandra was prescribed for inflammatory diseases including hepatitis, asthma and orchitis (Warrier et al., 1994). The hepatoprotective activity exerted by Trianthema decandra ( $Z$. decandra) in carbon tetrachloride-induced liver damage indicating less or no toxic effects (Sengottuvelu et al., 2008). In total, 25 phytocompounds were reported in $n$-hexane fraction of $Z$. decandra from which 6-octadecenoic acid has cancer preventive property and $n$-hexadecanoic acid is known as an anti-inflammatory compound (Malarvizhi et al., 2015). The unsaturated fatty acid oleic acid was isolated from the ethanolic extract of $Z$. decandra (Malarvizhi et al., 2016) and found to exert anti-cancer activity through a variety of mechanisms (Carrillo et al., 2012). The 
present study is aimed at delineating the anti-cancer activity of $Z$. decandra in HCT-116 colon cancer cells through MTT assay, mitochondrial membrane permeability assessment, induction of ROS, apoptosis and caspase activities.

\section{Materials and Methods}

\section{Cancer cell culture}

The HCT-116 colon cancer cells were procured from the National Center for Cell Science, Pune, India, and sustained in Dulbecco's modified Eagles medium, containing $10 \%$ fetal bovine serum and $1 \%$ antibiotic

\section{Box 1: MTT Assay}

\section{Principle}

The viable cells have $\mathrm{NAD}(\mathrm{P}) \mathrm{H}$-dependent oxidoreductase which reduces the yellow colored MTT reagent to deep purple colored formazan (an insoluble crystal). The darker the solution is due to the greater number of viable and metabolically active cells.

\section{Requirements}

MTT (3-[4,5-dimethylthiazol-2-yl]-2,5 diphenyl tetrazolium bromide); Plateshaker; Singla channel pipette $(0.001-1 \mathrm{~mL})$; Multichannel pipette (0.01-0.3); Class 2B hood Benchtop centrifuge; Multiwell plate reader (Biotek, Microplate Reader ELx800TM); Incubator with $5 \% \mathrm{CO}_{2}$ at $37^{\circ} \mathrm{C}$; Microplates-96 well; round or flat bottom well; Magnetic stirrer; Filter (0.22 $\mathrm{mm}$ ); Methanol, ethanol, and dimethyl sulfoxide; Formazan; HCT-116 cells (NCCS, Pune, India); Dulbecco's modified Eagle's medium culture (serum-free low sugar)

\section{Procedure}

\section{Preparation of MTT solution}

Step 1: Dissolve MTT powder (500 mg) in phosphate buffer solution ( $5 \%$ solution; $10 \mathrm{~mL}$ )

Step 2: Use a magnetic stirrer to stir the solution for approximately 1 hour in the dark

Step 3: Use a filter $(0.22 \mathrm{~mm})$ to sterilize the solution and store in $10-\mathrm{mL}$ aliquot at $-20^{\circ} \mathrm{C}$

Step 4: Unused MTT may be frozen and reused

Incubation of cells

Day 1

Step 1: Add HCT-116 cells into the $5 \mathrm{~mL}$ Dulbecco's modified Eagle's medium culture

Step 2: Centrifuge the medium in a sterile falcon tube $(15 \mathrm{~mL})$ at $500 \mathrm{rpm}$ for $5 \mathrm{~min}$

Step 3: Remove the media and resuspend cells to culture medium $(1.0 \mathrm{~mL})$

Step 4: Count and record cells per $\mathrm{mL}$ aseptically

Step 5: Dilute the cells to $10^{6}$ cells/mL. Use the Dulbecco's modified Eagle's medium to dilute cells

Step 6: Add $100 \mu \mathrm{L}$ of cells ( $10^{5}$ total cells) into each well and incubate for 24 hours and antimycotic solution [penicillin (100 units/mL), streptomycin $(100 \mathrm{mg} / \mathrm{mL})$ and amphotericin $(25 \mu \mathrm{g} /$ $\mathrm{mL})$ ]. The HCT-116 cells were cultured in a $\mathrm{CO}_{2}$ incubator at $37^{\circ} \mathrm{C}$. The cells were harvested using trypsinEDTA and subcultured. All standard culture reagents were procured from the Invitrogen (USA). A stock solution of $10 \mathrm{mg} / \mathrm{mL}$ of $Z$. decandra was prepared in DMSO and sterile-filtered using $0.22 \mu \mathrm{m}$ filter on the day of experiment. The extract was diluted to the required concentration (final concentration of DMSO not exceeding $0.05 \%)$.

\section{Preparation of ethanolic extract}

The roots $(100 \mathrm{~g})$ of $\mathrm{Z}$. decandra were washed with

\section{Day 3}

Step 1: When removing the media, do it carefully in order to avoid variation in data

Step 2: Final volume should be $100 \mu \mathrm{L} /$ well

Step 3: Treat the cells with a) no drug (untreated control); $Z$. decandra at indicated concentrations $(0-250 \mu \mathrm{g} / \mathrm{mL}$ at indicated time points).

Step 4: Cells are plated in triplicate to minimize the variation in results. Incubate the cells for 48 hours

Day 6

Step 1: Remove the medium and wash cells with phosphate buffer solution

Step 2: Add $100 \mu \mathrm{L}$ of $0.5 \mathrm{mg} / \mathrm{mL}$ MTT to each well. All should be done aseptically

Step 3: Use a plateshaker to shake the plate for $5 \mathrm{~min}$ (slowly increasing the shaking speed: maximum 900 shakes/min)

Step 4: Then incubate the plate in a $\mathrm{CO}_{2}$ incubator for another 4 hours at $37^{\circ} \mathrm{C}$, depending on the cell type until the intracellular formazan crystals are visible under a microscope

Step 5: Dimethyl sulfoxide $(5 \%, 100 \mu \mathrm{L})$ is added to each well and resuspend until all crystals have been dissolved

Step 6: Using a multichannel pipette to mix each well thoroughly

Step 7: Measure the absorbance at $595 \mathrm{~nm}$ using the microplate reader

\section{Precautions}

MTT is toxic and harmful. There may be irritation of the skin and eye. Therefore, use equipment for personal protection.

MTT is light sensitive. The bottle containing MTT solution should be covered with aluminum foil to protect from light.

\section{Absorbance values}

The absorbance readings should be within 0.75 and 1.25 . If the reading is too low, then increase the number of cells plated or the incubation time, and make sure that the cell culture condition is appropriate.

\section{References}

Slater et al., 1963; Gunaseelan et al., 2017

References (video)

Wang et al., 2018 
distilled water, shade dried and powdered by a grinder. The powdered sample $(30 \mathrm{~g})$ was then extracted with ethanol (1: 5 ratio). The extract was concentrated at $40^{\circ}$ $\mathrm{C}$ under reduced pressure using a rotary evaporator (Supervac, India) and it was stored in an air tight container $\left(4^{\circ} \mathrm{C}\right)$ for future use.

\section{ROS generation assay}

A non-fluorescent probe (DCFH-DA) was used to measure the intracellular ROS generation, which readily entered the cytoplasm of cells. The probe was hydrolyzed by esterase to form dichlorofluorescein (DCF), which interacts with ROS and emits fluorescence. The intensity of the fluorescence corresponds to ROS generation (Jesudason et al., 2008). $1 \times 10^{6}$ cells/well were seeded in 6-well plate and treated with $\mathrm{Z}$. decandra extract at $100 \mu \mathrm{g} / \mathrm{mL}$ concentration. Then, the cells were incubated with the probe for $10 \mathrm{~min}$ at $37^{\circ} \mathrm{C}$. The amount of ROS generated was calculated by determining the fluorescent intensities at 485 and $530 \mathrm{~nm}$.

\section{Assessment of mitochondrial membrane potential}

The mitochondrial membrane potential $(\Delta \psi \mathrm{M})$ was assessed using rhodamine-123 (Johnson et al., 1981). The cells were cultured in 6-well plate $\left(1 \times 10^{6}\right.$ cells $/$ well), and they reacted with $Z$. decandra. The cells were further incubated with rhodamine-123 dye for $30 \mathrm{~min}$. The mitochondrial membrane permeability was assessed using a floid cell imaging station (Invitrogen, USA). Subsequently, the cells were detached using trypsin and subjected to fluorescence intensity analysis at 485 $\mathrm{nm}$ (excitation) and $530 \mathrm{~nm}$ (emission) using spectrofluorometer (Shimadzu, USA). The fluorescence image was captured and the representative images were used for comparison. To quantitate the data, the fluorescence was measured spectrofluorometrically.

\section{Determination of Caspase-3 and 9}

The levels of initiator and executor caspases were determined in the spent media following the manufacturer's directions using a colorimeter ( $R$ \& D systems, USA). The harvested cells were lysed using chilled $50 \mu \mathrm{L}$ lysis buffer and spun at $10,000 \times \mathrm{g}$ for $60 \mathrm{sec}$. Then, the supernatant was incubated with buffered substrate for caspase- 3 and 9 and placed at $37^{\circ} \mathrm{C}$ for 2 hours. The released pNA ( $\mathrm{p}$-nitroaniline) was assessed colorimetrically at $405 \mathrm{~nm}$.

\section{Apoptotic morphological changes}

The cultured cells were fixed in 6-well plate $\left(3 \times 10^{4} /\right.$ well) and incubated with glacial acetic acid/methanol (1:3) for $30 \mathrm{~min}$ at $4^{\circ} \mathrm{C}$. This was followed by washing the cells with phosphate buffer solution and subsequently staining with acridine orange/ethidium bromide for $30 \mathrm{~min}$ at $37^{\circ} \mathrm{C}$. The stained cells were subjected to washing to remove nonspecific stains with phosphate buffer solution and visualized using fluorescence microscopy (Invitrogen, USA). The HCT-116 cells stained with ethidium bromide is indicated by arrow marks (Karthikeyan et al., 2011).

\section{Statistical analyses}

The experiments were conducted in triplicates and the results obtained were expressed as the mean \pm standard deviation. Significance was calculated using one-way ANOVA and student ' $\mathrm{t}$ ' test. $\mathrm{P}<0.05$ indicated a significant difference.

\section{Results}

\section{Cytotoxicity of ethanolic extract on HCT-116 cells}

Based on the MTT assay result Z. decandra was found to have cytotoxic effect against HCT-116 cells. Its $\mathrm{IC}_{50}$ value was $96.8 \mu \mathrm{g} / \mathrm{mL}$ (Figure 1).

\section{Measurement of intracellular ROS generation}

The intracellular generation of ROS measured using DFC-DA florescent assay indicated the excessive generation of ROS in the cells treated with $\mathrm{Z}$. decandra extract $(100 \mu \mathrm{g} / \mathrm{mL})$ as evidenced by enhanced florescence (Figure 2).

\section{Mitochondrial membrane potential (MMP)}

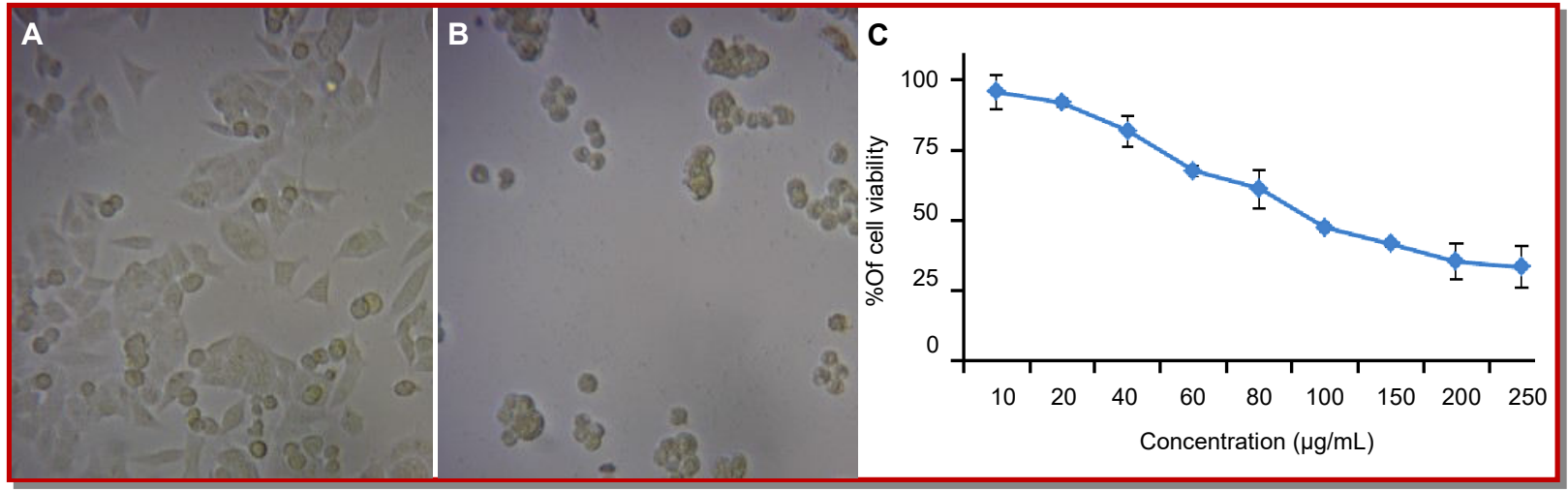

Figure 1: Photomicrographs of the control (A), Z. decandra (100 $\mu \mathrm{g} / \mathrm{mL})$-treated cells (B) and cytotoxicity of Z. decandra on HCT-116 cells (C) 


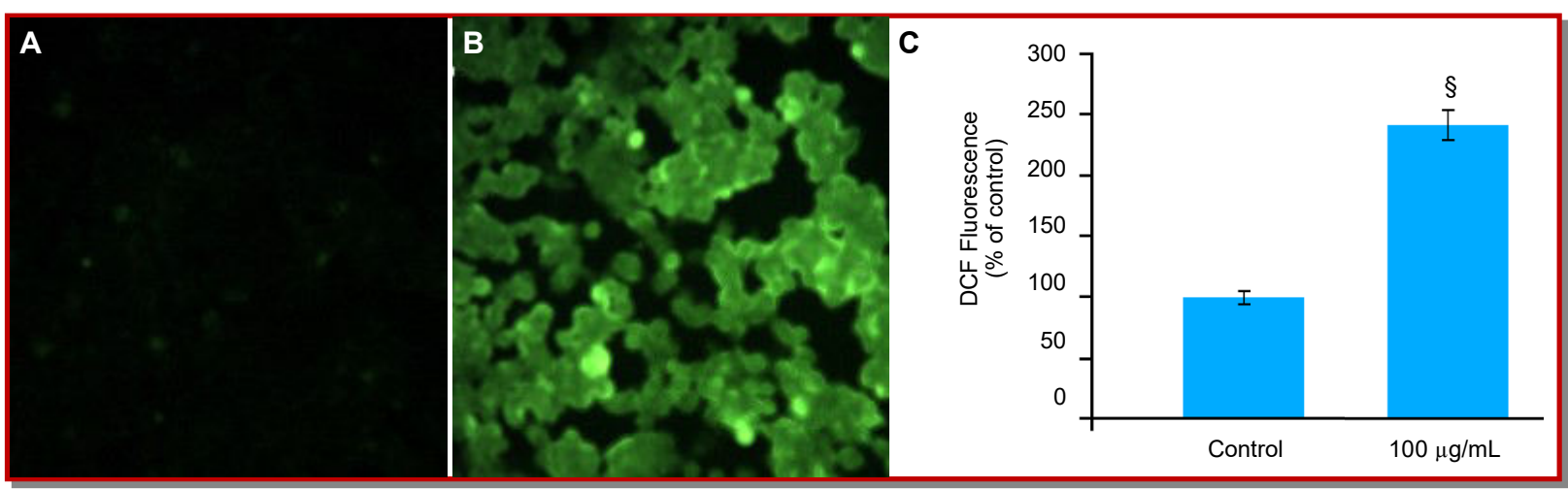

Figure 2: The fluorescence gradient in control (A) and Z. decandra-treated cells (B). Levels of intracellular ROS were determined using DCF-DA (C), which is membrane present and acted on by esterase to DCF which reacts to give fluorescence. Fluorescence intensity was measured using spectroflurometer at 485 and $530 \mathrm{~nm}$. Results are represented as average values of three independent experiments; $§$ indicates statistical significance $(\mathrm{p}<0.05)$

The treated cells displayed a drastic reduction in the rhodamin binding indicating reduced mitochondrial activity (Figure 3).

\section{Determination of Caspase-3 and 9}

A significant increase in the level of caspase 3 and 9 was evident after treatment with $Z$. decandra indicating that the apoptotic effect of $Z$. decandra was possibly mediated through caspase 3 and 9 (Figure 4).

\section{Determination of apoptotic morphological changes}

To address the functional relevance of enhanced ROS production in HCT-116 cells, acridine orange/ethidium bromide staining was performed which indicated the presence of ethidium bromide uptake in cells treated with Z. decandra (Figure 5).

\section{Discussion}

ROS generation is one of the most important strategies adopted by many therapies including radiation. Targeting ROS using antioxidants such as EGCG has been reported to reduce cancer cell survival (Muthusami et al., 2013). The paradoxical role of ROS is well established in tumor proliferation and suppression. NADPH oxidase is considered an important source known to generate ROS. This enzyme is present abundantly in mitochondria. The increase in the generation of ROS in Z. decandra treated cells indicate that the phytoconstituents present in the extract alone or in combination could have targeted NAPDH oxidase while exerting anti-proliferative effects.

This contention is further strengthened by MTT assay which evaluates the mitochondrial dehydrogenase activity. Taken together it is presumed that $Z$. decandra activates NAPDH oxidases could inhibit dehydrogenases leading to augmented production of free radicals and reduce cell viability. In addition, Z. decandra also upregulated the levels of initiator caspase and effector caspase indicating the onset of apoptosis. It is pertinent to link the relationship between enhanced ROS generation and induction of apoptosis. Many of the pharmaceutical drugs increase the production of ROS and reduce the viability of cells; it will be interesting to

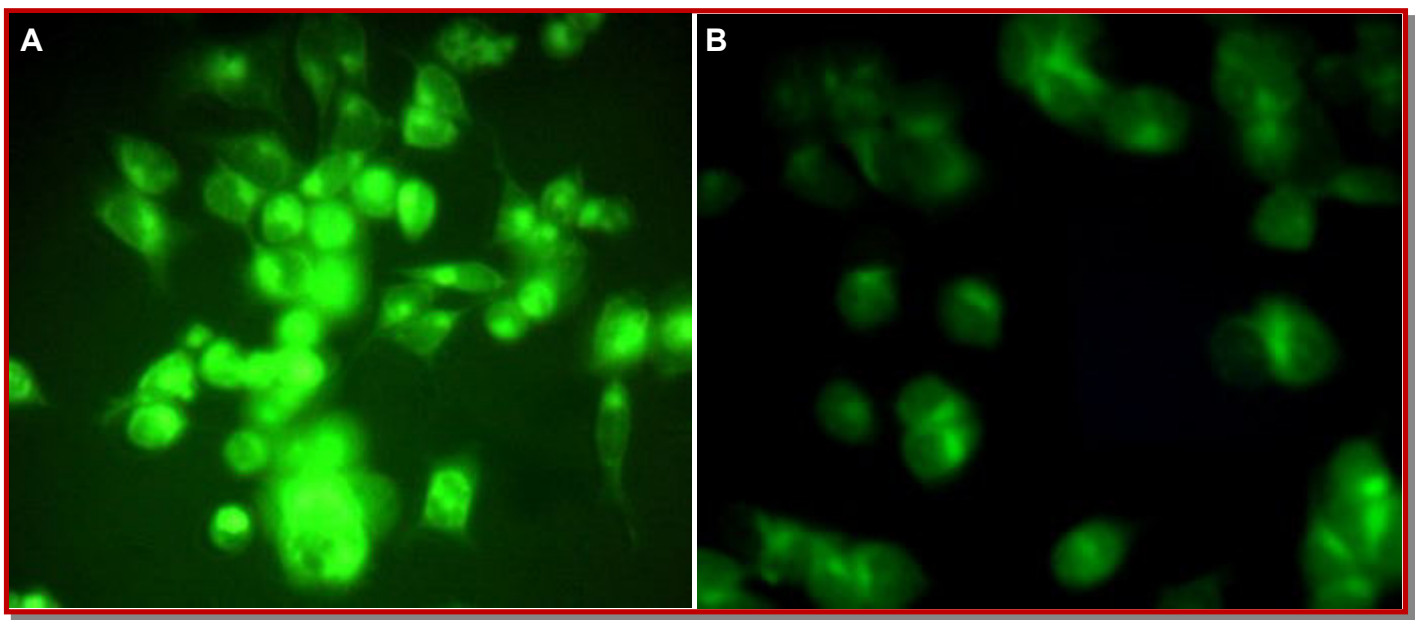

Figure 3: Permeability in Z. decandra-treated cells (B) when compared with control cells (A) using rhodamine-123 dye 


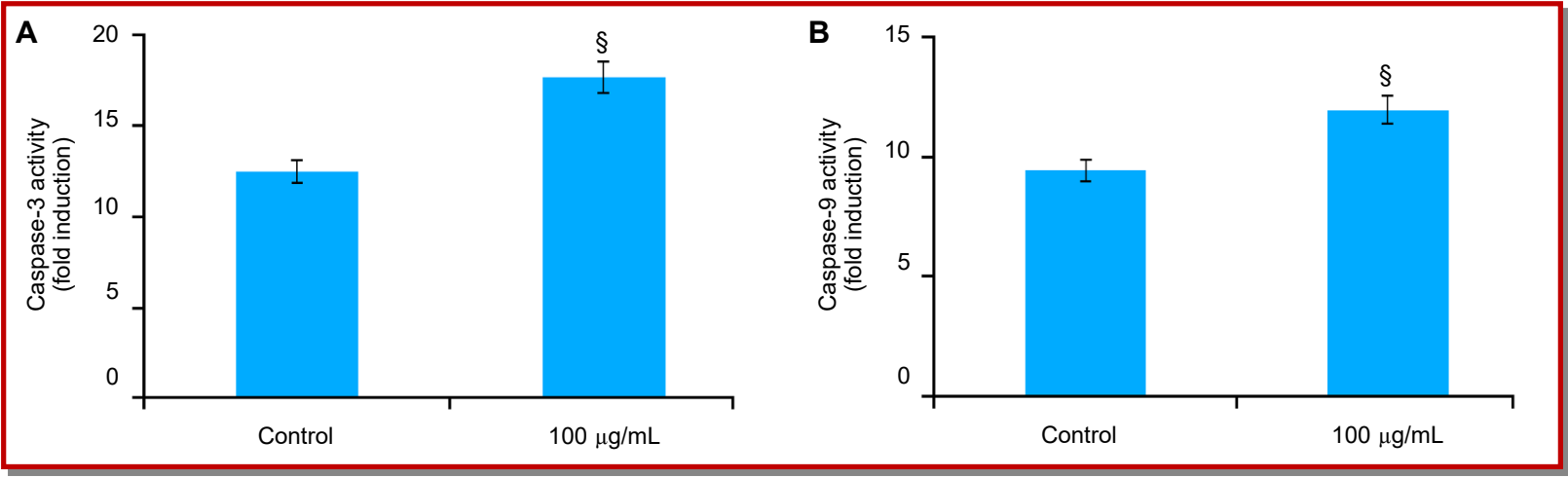

Figure 4: Effect of Z. decandra on the levels of initiator and effector caspases [caspase 3 (A) and caspase 9 (B)] in the conditional medium were evaluated and represented. Results are represented as average values of three independent experiments; $§$ indicates statistical significance $(\mathrm{p}<0.05)$. Significance was calculated using one-way ANOVA and student ' $t$ ' test.

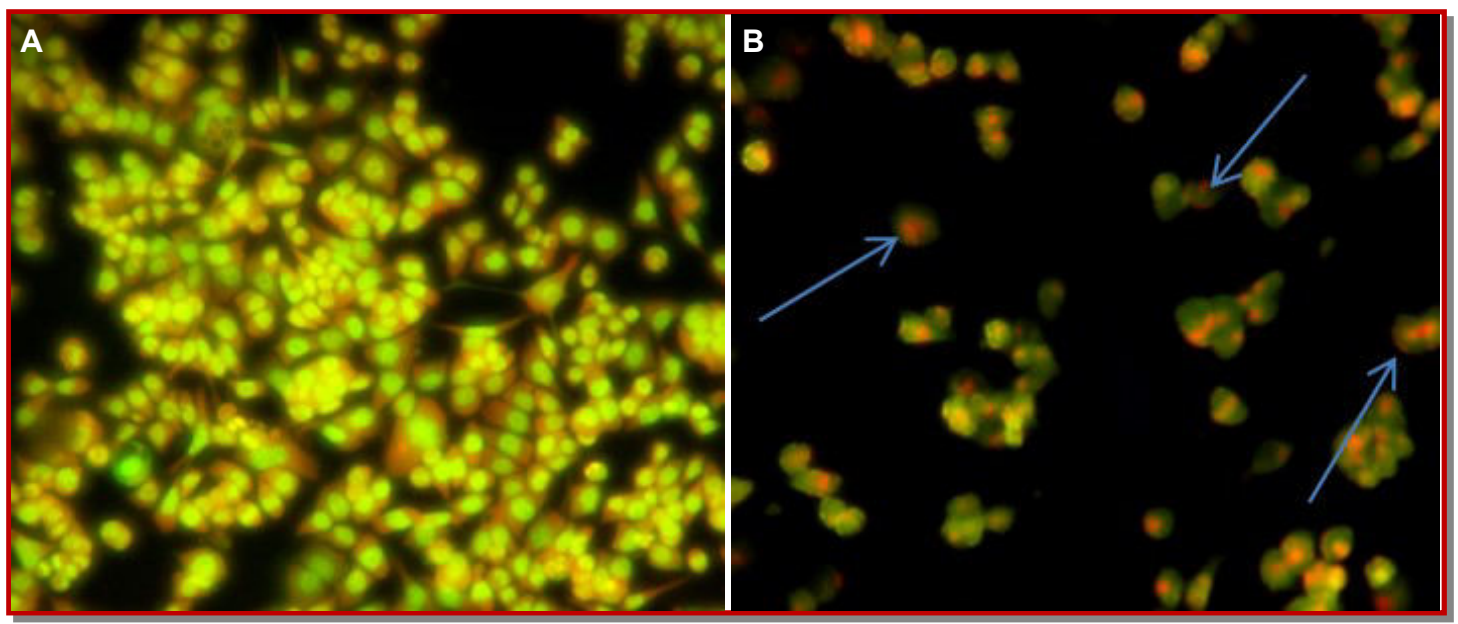

Figure 5: Stains the acridine orange/ethidium bromide staining in control (A) and Z. decandra-treated (B) HCT-116 cells. Arrow marks indicate the DNA damage as evidenced by nuclear staining with ethidium bromide

find out the cellular mechanisms behind the increased ROS levels in $Z$. decandra treated cells. The phytoconstituents of $\mathrm{Z}$. decandra could have also attenuated antioxidant enzymes such as SOD, Gpx and Trx in addition to xanthine oxidase. A number of treatment regimens such as radiation, hypericin, cisplatin and cordycepin are known to produce ROS and induce cellular death/ senescence (Seong et al., 2016). Further studies are required to know the role of $Z$. decandra on the enzymatic activity in HCT-116 Colon cancer cells in vitro to arrive at a definitive conclusion. However, the present study clearly supports the anticancer properties of $\mathrm{Z}$. decandra and promises to be an alternative therapeutic/ preventive source to conventional treatments as the toxicity studies carried out using animal model systems show no significant difference. The high levels of ROS generated by $Z$. decandra might have contributed to the reduced mitochondrial membrane potential. A number of studies report an inverse correlation between accumulation ROS and mitochondrial membrane permeability (Looi et al., 2013). The present study reports the efficacy of $Z$. decandra in inducing cellular apoptosis and the involvement of ROS generation, alteration in the MMP and enhanced induction of caspases. Many of the mitogenic signaling to increase the cancer cell proliferation is mediated by $\mathrm{PI} 3 \mathrm{~K} /$ Akt signaling. ROS regulates PI3 kinase signaling and inhibits the activation of Akt, a key protein required for the survival of cells, and an increase in ROS generation by $Z$. decandra is also associated with reduced viability indicating the possible regulatory role of phytoconstituents of Z. decandra on PI3 kinase and Akt signaling. The increased activities of caspase in $Z$. decandra treated cells indicate effective initiation and execution of apoptosis. Taken together the enhanced ROS generation and uptake of ethidium bromide indicate the onset of apoptosis in cells treated with $Z$. decandra to delineate effect of $Z$. decandra. ROS induced DNA damage by $Z$. decandra in colon cancer cell is evident as stained by acridine orange/ethidium bromide, which could probably be mediated by ROS induced inhibition of PARP-1 by the constituents present in Z. decandra. 


\section{Conclusion}

This study reports the efficacy of Z. decandra in inducing apoptosis through ROS generation and altering mitochondrial activity in HCT-116 colon cancer cells.

\section{Funding}

The financial assistance to D. Malarvizhi (IF140802) in the form of DST-Inspire Fellowship by Department of Science and Technology is greatly acknowledged.

\section{Conflict of Interest}

Authors declare no conflict of interest.

\section{Acknowledgements}

The authors are grateful to the Managing Director, CEO and Vice Chancellor, Karpagam Academy of Higher Education for their support and directions and establishment of laboratory facilities.

\section{References}

Al-Emam A, Al-Shraim M, Eid R, Alfaifi M, Al-Shehri M, Moustafa MF, Radad K. Ultrastructural changes induced by Solanum incanum aqueous extract on HCT 116 colon cancer cells. Ultrastruct Pathol. 2018; 42: 255-61.

American Cancer Society. Colorectal cancer facts and figures 2017-2019. 2017.

Baas J, Krens L, Bohringer S, Mol L, Punt C, Guchelaar HJ, Gelderblom H. Genome wide association study to identify predictors for severe skin toxicity in colorectal cancer patients treated with cetuximab. PloS One. 2018; 13: e0208080.

Berger J, Lester P, Rodrigues L. Medical therapy of malignant bowel obstruction with octreotide, dexamethasone, and metoclopramide. Am J Hosp Palliat Med. 2016; 33: 407-10.

Bray F, Ferlay J, Soerjomataram I, Siegel RL, Torre LA, Jemal A. Global cancer statistics 2018: GLOBOCAN estimates of incidence and mortality worldwide for 36 cancers in 185 countries. CA Cancer J Clin. 2018; 68: 394-424.

Buttacavoli M, Albanese NN, Di Cara G, Alduina R, Faleri C, Gallo M, Pizzolanti G, Gallo G, Feo S, Baldi F, Cancemi P. Anti-cancer activity of biogenerated silver nanoparticles: An integrated proteomic investigation. Oncotarget 2017; 9: 9685-705

Carrillo C, Cavia Mdel M, Alonso-Torre SR. Antitumor effect of oleic acid: Mechanisms of action. A review. Nutr Hosp. 2012; 27: 1860-65.

Chen G, Yang Y, Hu C, Cheng X, Xu Y, Cai X, Wang M, Yang CS, Cao P. Protective effects of huangqin decoction against ulcerative colitis and associated cancer in mice. Oncotarget 2016; 7: 61643-55.

Ewald JA, Desotelle JA, Wilding G, Jarrard DF. Therapyinduced senescence in cancer. J Natl Cancer Inst. 2010; 102: $1536-46$.

Fukutake M, Yokota S, Kawamura H, lizuka A, Amagaya S, Fukuda K, Komatsu Y. Inhibitory effect of Coptidis rhizoma and Scutellariae radix on azoxymethane-induced aberrant crypt foci formation in rat colon. Biol Pharm Bull. 1998; 21: 814-17.

Giuliani J, Marzola M. Skin rash during cetuximab treatment in advanced colorectal cancer: Is age a clinical predictor? J Gastrointest Cancer. 2013; 44: 241-45.

Gunaseelan S, Balupillai A, Govindasamy K, Ramasamy K, Muthusamy G, Shanmugam M, Thangaiyan R, Robert BM, Prasad Nagarajan R, Ponniresan VK, Rathinaraj P. Linalool prevents oxidative stress activated protein kinases in single UVB-exposed human skin cells. PLoS One. 2017; 12: e0176699.

Jainu M, Vijaimohan K, Kannan K. Cissus quadrangularis L. extract attenuates chronic ulcer by possible involvement of polyamines and proliferating cell nuclear antigen. Pharmacogn Mag. 2010; 6: 225-33.

Jesudason EP, Masilamoni JG, Jebaraj CE, Paul SFD, Jayakumar R. Efficacy of DL-a lipoic acid against systemic inflammation induced mice: Antioxidant defense system. Mol Cell Biochem. 2008; 313: 113-23.

Johnson LV, Walsh ML, Bockus BJ, Chen LB. Monitoring of relative mitochondrial membrane potential in living cells by fluorescence microscopy. J Cell Biol. 1981; 88: 526-35.

Karthikeyan S, Kanimozhi G, Prasad NR, Mahalakshmi R. Radiosensitizing effect of ferulic acid on human cervical carcinoma cells in vitro. Toxicol in vitro. 2011; 25: 1366-75.

Kee JY, Han YH, Mun JG, Um JY, Hong SH. Pharmacological effect of prohibited combination pair Panax ginseng and Veratrum nigrum on colorectal metastasis in vitro and in vivo. J Ethnopharmacol. 2018; 220: 177-87.

Looi CY, Arya A, Cheah FK, Muharram B, Leong KH, Mohamad K, Wong WF, Rai N, Mustafa MR. Induction of apoptosis in human breast cancer cells via caspase pathway by vernodalin isolated from Centratherum anthelminticum (L.) seeds. PLoS One. 2013; 8: e56643.

Malarvizhi D, Anusooriya P, Meenakshi P, Sowmya S, Perumal PC, Oirere EK, Gopalakrishnan VK. Anti-oxidant properties and analysis of bioactive compounds present in nhexane root extract of Zaleya decandra. Int J Pharm Sci Rev Res. 2015; 34: 118-23.

Malarvizhi D, Anusooriya P, Meenakshi P, Sundaram S, Oirere E, Gopalakrishnan VK. Isolation, structural characterization of oleic acid from Zaleya decandra root extract. Anal Chem Lett. 2016; 6: 669-77.

Meenakshi P, Bhuvaneshwari R, Rathi MA, Thirumoorthi L, Guravaiah DC, Jiji MJ, Gopalakrishnan VK. Antidiabetic activity of ethanolic extract of Zaleya decandra in alloxaninduced diabetic rats. Appl Biochem Biotechnol. 2010; 162: 1153-59. 
Munker S, Gerken M, Fest P, Ott C, Schnoy E, Fichtner-Feigl S, Wiggermann P, Vogelhuber M, Herr W, Stroszczynski C, Schlitt HJ, Evert M, Reng M, Klinkhammer-Schalke M, Teufel A. Chemotherapy for metastatic colon cancer: No effect on survival when the dose is reduced due to side effects. BMC cancer. 2018; 18: 455.

Muthusami S, Prabakaran DS, Yu JR, Park WY. EGF-induced expression of Fused Toes Homolog (FTS) facilitates epithelial -mesenchymal transition and promotes cell migration in ME180 cervical cancer cells. Cancer Lett. 2014; 351: 252-59.

Sengottuvelu S, Srinivasan D, Duraisami R, Nandhakumar J, Vasudevan M, Sivakumar T. Hepatoprotective activity of Trianthema decandra on carbon tetrachloride-induced hepato- toxicity in rats. Int J Green Pharm. 2008; 2: 122-25.

Wang Y, Chen J, Wang J, Guo X, Wang N, Yuan J. Antidepressant, neuropharmacological activity and mode of action of theaflavin-3-gallate in in vitro and in vivo models of depression. Bangladesh J Pharmacol. 2018; 13: 340-48.

Warrier PK, Nambiar VPK, Ramankutty C. Indian medicinal plants a compendium of 500 species. vol. 1. India, Orient Longman Pvt Ltd., 1993, pp 349-351.

Zhang R, Yu Q, Lu W, Shen J, Zhou D, Wang Y, Gao S, Wang Z. Grape seed procyanidin B2 promotes the autophagy and apoptosis in colorectal cancer cells via regulating PI3K/Akt signaling pathway. Onco Targets Ther. 2019; 12: 4109-18. 